\title{
A vantagem comparativa do regime fiscal do residente não habitual em Portugal
}

\section{The comparative advantage of the tax regime of the non-habitual resident in Portugal}

\author{
José de Campos Amorim \\ Instituto Superior de Contabilidade e Administração do Porto, Portugal \\ j.camposamorim@gmail.com
}

\begin{abstract}
Resumo
O regime fiscal do residente não habitual $(\mathrm{RNH})$ é particularmente atrativo para os não residentes que exercem atividades de elevado valor acrescentado, quer sejam trabalhadores dependentes, independentes, pensionistas ou membros de órgãos estatutários de pessoas coletivas que pretendem obter uma residência em Portugal para aí beneficiarem de vantagens fiscais. Numa análise comparativa com outros países, o regime português confere maior benefício fiscal aos não residentes que pretendem fixar a sua residência em Portugal.
\end{abstract}

Palavras-chave: residente não habitual; investimento estrangeiro; benefício fiscal.

\begin{abstract}
The tax regime of the non-habitual resident $(\mathrm{RNH})$ is particularly attractive for non-residents who practice high value-added professional activities, and for employed or self-employed workers, retired people, or members of statutory bodies of legal entities who want to obtain residency in Portugal in order to receive tax benefits. In a comparative analysis with other countries, the Portuguese regime confers greater tax benefits to non-residents who intend to establish their residence in Portugal.
\end{abstract}

Keywords: non-habitual resident; foreign investment; tax benefits.

\section{Introdução}

No contexto de concorrência fiscal internacional impunha-se a criação de novos instrumentos de captação de investimento externo. Um dos instrumentos adotado é o regime fiscal do residente não habitual (RNH), que procura, com a redução da carga fiscal, atrair novos investidores e impedir a deslocalização do "contribuinte volátil" para ambientes fiscais mais atrativos (Nascimento, Graça \& Ramos, 2010: 858).

A necessidade de introdução do regime fiscal do RNH já vinha a ser reclamada desde 2008. O artigo $126 .^{\circ}$ da Lei n. ${ }^{\circ} 64-\mathrm{A} / 2008$, de 31 de dezembro, autorizava o Governo a criar um regime fiscal para RNH em sede de IRS. Este regime foi introduzido no Código do Imposto Sobre o Rendimento das Pessoas Singulares (CIRS) pelo Decreto-Lei n. ${ }^{\circ}$ 249/2009, de 23 de setembro, que cria o Código Fiscal do Investimento (CFI), entretanto revogado pelo DecretoLei n. ${ }^{\circ}$ 162/2014, de 31 de outubro, que aprova um novo CFI.

Dos Algarves: A Multidisciplinary e-Journal, 31- 2017.

ISBN 2182-5580 @ ESGHT - University of the Algarve, Portugal.

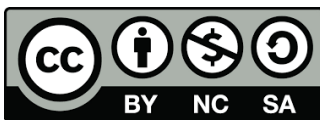

To cite this article: J.C. Amorim (2017). A vantage comparative do regime fiscal do residente não habitual em Portugal. Dos Algarves: A Multidisciplinary e-Journal, 31, 1-14. doi: 10.18089/DAMeJ.2017.31.1 
Portugal criou um regime fiscal particularmente atrativo para quadros altamente qualificados em atividades de elevado valor acrescentado, mas também pessoas com elevado património (Ferreira \& Gonçalves, 2012), designados por High Net Worth Individuals (HNWI), que se movem essencialmente por motivos de ordem fiscal (Borges \& Sousa, 2011), garantindo o acesso a condições fiscais mais favoráveis do que noutros países.

A atração fiscal destas pessoas é possível de duas formas distintas (Borges \& Sousa, 2011: 713): através do método da isenção na eliminação da dupla tributação internacional dos rendimentos de fonte estrangeira obtidos por $\mathrm{RNH}$, ou através de uma tributação mitigada e proporcional de certos rendimentos do trabalho dependente e independente (incluindo os obtidos em Portugal), auferidos por sujeitos passivos de IRS a quem seja reconhecida esta qualidade.

O regime fiscal dos RNH visa os não residentes, trabalhadores dependentes ou independentes qualificados em atividades de elevado valor acrescentado, e inclui também os membros de órgãos estatutários de entidades coletivas, interessados em estabelecer uma residência temporária em Portugal. Portugal não é o único país com regime de tributação para os RNH, mas é um dos que consagrou um regime privilegiado de tributação e o mais competitivo em termos fiscais.

Face à diversidade de situações abrangidas, proceder-se-á à análise dos requisitos legais destinados à atribuição deste estatuto e de seguida à sua comparabilidade.

\section{Enquadramento normativo}

O regime fiscal do RNH insere-se hoje num quadro normativo específico, que tem por base o Decreto-Lei n. ${ }^{\circ}$ 249/2009, de 23 de setembro, que aprovou o CFI, alterado sucessivamente pela Lei n. ${ }^{\circ}$ 20/2012, de 14 de maio, pelo Decreto-Lei n. ${ }^{\circ} 82 / 2013$, de 17 de junho, pela Lei n. ${ }^{\circ} 83-$ $\mathrm{C} / 2013$, de 31 de dezembro e pelo Decreto-Lei n. ${ }^{\circ} 162 / 2014$, de 31 de outubro, que procedeu à revisão do regime dos benefícios fiscais ao investimento produtivo e respetiva regulamentação, alterando, para o efeito, o Estatuto dos Benefícios Fiscais (EBF), aprovado pelo Decreto-Lei $.^{\circ} 215 / 89$, de 1 de julho.

Integram o regime fiscal do $\mathrm{RNH}$ as atividades de elevado valor acrescentado, com carácter científico, artístico ou técnico, conforme prevê o n..$^{\circ} 6$ do artigo $72 .^{\circ}$ e o n. 4 do artigo $81 .^{\circ}$ do CIRS. Tais atividades estão definidas na Portaria n. ${ }^{\circ} 12 / 2010$, de 7 de janeiro, a qual faz referência às atividades de arquitetos, engenheiros e técnicos similares, artistas plásticos, atores e músicos, auditores e consultores fiscais, médicos e dentistas, professores universitários, psicólogos, profissões liberais, técnicos e assimilados e investidores, administradores e gestores.

$\mathrm{Na}$ verdade, trata-se de atrair dois tipos principais de destinatários (Nascimento et al., 2010: 861):

-Não residentes, que exercem atividades de elevado valor acrescentado no estrangeiro, "dispostos a estabelecer domicílio em Portugal de forma permanente, passando, por essa via, a ser residentes fiscais em Portugal”, e;

-Não residentes, que, "sendo trabalhadores dependentes, independentes ou membros de órgãos estatutários de pessoas coletivas, apenas pretendem estabelecer em Portugal uma residência temporária" para aí auferir rendimentos, em virtude de terem sido destacados ou expatriados. 
O objetivo deste regime, de natureza dual, é de atrair para o território português profissionais não residentes, qualificados em atividades de elevado valor acrescentado, bem como beneficiários de pensões obtidas no estrangeiro, à semelhança do que tem vindo a suceder noutros países, nomeadamente na Suíça, Inglaterra, Espanha e França (Borges \& Sousa, 2011).

\section{Requisitos de atribuição do regime do RNH}

Para serem tributados como RNH, estes devem preencher os requisitos previstos na Circular 2/2010, 1 de 6 de maio, isto é:

a) Tornarem-se fiscalmente residentes em território português de acordo com qualquer dos critérios estabelecidos no n. $^{\circ} 1$ do artigo $16 .^{\circ}$ do Código do IRS;

b) Comprovarem, no momento da inscrição, a anterior residência e tributação no estrangeiro, através de certificado de residência demonstrando a tributação efetiva;

c) Não terem em qualquer dos cinco anos anteriores sido tributados como residentes em sede de IRS.

Para a obtenção do estatuto de RNH, o sujeito passivo deve, nos termos do n..$^{\circ} 10$ do art. ${ }^{\circ} 16 .^{\circ}$ do CIRS, "solicitar a inscrição como residente não habitual, por via eletrónica, no Portal das Finanças, posteriormente ao ato da inscrição como residente em território português e até 31 de março, inclusive, do ano seguinte àquele em que se torne residente nesse território." O RNH não pode ter sido residente em território português em qualquer um dos cinco anos anteriores àquele em que pretenda que tenha início a tributação como RNH. É "necessário um hiato de 5 anos de ausência de residência fiscal em Portugal” (Borges \& Sousa, 2011: 726). Na dúvida, a Direção de Serviços de Registo de Contribuintes (DSRC) poderá solicitar ao RNH que comprove a sua residência no estrangeiro ou a sua tributação no estado de origem, podendo exigir um certificado de residência atestando a existência de relações pessoais ou económicas com o Estado estrangeiro nos últimos cinco anos (cf. Circular n. ${ }^{\circ}$ 9/2012, de 3 de agosto). ${ }^{2}$

Os sujeitos passivos requerentes da categoria 8 - Investidores, administradores e gestores - podem ser chamados a apresentar os documentos (procurações, certidões da conservatória do registo comercial, atas, etc.) para comprovar as respetivas qualidades de administradores/gerentes/gestores e poderes de representação, de acordo com o n. 7 da Circular n. ${ }^{\circ}$ 2/2010, de 6 de maio e o.$^{\circ} 3$ da Circular n. ${ }^{\circ}$ 9/2012, de 3 de agosto.

Uma vez concedido o estatuto do RNH, dispõe o n. ${ }^{\circ} 11$ do artigo $16 .^{\circ}$ do CIRS que o gozo do "direito a ser tributado como residente não habitual em cada ano do período referido no n. ${ }^{\circ} 9$ (10 anos) depende de o sujeito passivo ser considerado residente em território português, em qualquer momento desse ano".

O sujeito passivo que seja considerado RNH adquire o direito a ser tributado em sede de IRS pelo período de dez anos consecutivos ou interpolados (não prorrogável) a partir do ano,

\footnotetext{
1 Disponível em https://info.portaldasfinancas.gov.pt/NR/rdonlyres/255A970C-6140-4221-A7DE68A70B171387/0/Circ_2_2010.pdf.

2 Disponivel em https://info.portaldasfinancas.gov.pt/NR/rdonlyres/6B739D49-3A65-49D6-8F95D13B7A7B55946/0/Circular_9_2012_res_n_habituais.pdf.
} 
inclusive, da sua inscrição no registo de contribuintes da Autoridade Tributária (AT) como residente em território português ( $\mathrm{n} .{ }^{\mathrm{os}} 9,11$ e 12 do artigo $16 .^{\circ}$ da CIRS).

Se neste período de dez anos o sujeito passivo não gozar do seu direito durante um ou mais anos, pode retomar o gozo do mesmo em qualquer dos anos remanescentes daquele período a partir do ano em que volte a ser considerado residente em território português, segundo o n. ${ }^{\circ} 12$ do artigo $16 .^{\circ}$ do CIRS.

O legislador entendeu não renovar ou prorrogar o período de dez anos (Lei n. ${ }^{\circ}$ 20/2012, de 14 de maio). A Lei n. ${ }^{\circ} 82-E / 2014$, de 31 de dezembro, vigente desde 1 de janeiro de 2015, manteve o princípio da improrrogabilidade e a garantia do gozo do estatuto do RNH pelo prazo de dez anos, seguidos ou interpolados. Assim, se o requerente preencher todos os requisitos, poderá obter o estatuto de RNH por um período de dez anos seguidos ou interpolados, não sendo este período renovável ou prorrogável.

\section{Tributação dos rendimentos de fonte portuguesa ou estrangeira}

Quanto à tributação dos rendimentos de fonte portuguesa, os rendimentos líquidos das categorias A e B (trabalho dependente e independente), previstos nos artigos $2 .^{\circ}$ e $3 .^{\circ}$ do CIRS, auferidos em atividades de elevado valor acrescentado, com caráter científico, artístico ou técnico (Portaria n. ${ }^{\circ}$ 12/2010, de 7 de janeiro), por RNH em território português, são tributados à taxa especial de $20 \%$ (taxa de retenção na fonte) para as categorias $\mathrm{A} \mathrm{e} \mathrm{H}$, de acordo com o n. 8 do art. $^{\circ} 99 .^{\circ}$ do CIRS, e taxa de retenção na fonte de $20 \%$ igualmente para os rendimentos da categoria $\mathrm{B}$, segundo a alínea d) do $\mathrm{n} .{ }^{\circ} 1$ do artigo $101 .^{\circ}$ do $\mathrm{CIRS}$, se não for exercida a opção pelo seu englobamento permitida pelo n. 8 do artigo $72 .^{\circ}$ do CIRS.

Os rendimentos das categorias A e B (considerados de elevado valor acrescentado), G, E, $\mathrm{F}$ e $\mathrm{H}$ (pensões de alimentos) dos RNH em Portugal podem ser englobados por opção dos titulares residentes em território português, segundo as alíneas c) a e) do $n .{ }^{\circ} 1$, do n. ${ }^{\circ} 5$, do n. ${ }^{\circ}$ 6 e do n. 8 do artigo $72 .^{\circ}$ do CIRS. Se o sujeito passivo optar pelo englobamento de rendimentos sujeitos às taxas especiais ou liberatórias, fica obrigado, segundo o $\mathrm{n}^{\circ} 3$ do artigo $22 .^{\circ}$, o artigo $71 .^{\circ}$ e o artigo $72 .^{\circ}$ do CIRS, a englobar a totalidade dos rendimentos da mesma categoria de rendimentos, conforme estipulado no n. ${ }^{\circ} 5$ do artigo $22 .^{\circ}$ do CIRS. De referir que os rendimentos de fonte estrangeira estão sujeitos ao regime de eliminação da dupla tributação internacional (Ferreira \& Gonçalves, 2012).

É aplicável o método de isenção aos rendimentos auferidos no estrangeiro pelos RNH em Portugal. Aos RNH em território português que obtenham no estrangeiro rendimentos da categoria A aplica-se o método da isenção, segundo o n. $^{\circ} 4$ do artigo $81 .^{\circ}$ do CIRS, bastando que se verifique qualquer das condições seguintes:

- Sejam tributados no outro Estado de origem (Estado contratante), em conformidade com a convenção para eliminar a dupla tributação (CDT) celebrada entre Portugal e esse Estado; ou

- Sejam tributados no outro país, território ou região, nos casos em que não exista CDT, desde que os rendimentos em questão, pelos critérios previstos no $n .^{\circ} 1$ do artigo $18 .^{\circ}$ do CIRS, não sejam de considerar obtidos em território português.

Aos RNH em território português que obtenham, no estrangeiro, rendimentos da categoria B, auferidos em atividades de prestação de serviços de elevado valor acrescentado, 
com caráter científico, artístico ou técnico, definidos na Portaria n. ${ }^{\circ}$ 12/2010, de 7 de janeiro, ou provenientes da propriedade intelectual ou industrial, ou ainda da prestação de informações respeitantes a uma experiência adquirida no setor industrial, comercial ou científico, bem como das categorias $\mathrm{E}, \mathrm{F}$ e G, estão sujeitos ao método da isenção, conforme dispõe o.$^{\circ} 5$ do artigo $81 .^{\circ}$ do CIRS, bastando para tal que se verifique qualquer uma das condições seguintes:

- Possam ser tributados no outro Estado de origem (Estado contratante), em conformidade com a CDT celebrada por Portugal com esse Estado; ou

- Possam ser tributados no outro país, território ou região, em conformidade com o Modelo de Convenção Fiscal sobre o Rendimento e o Património da Organização de Cooperação e de Desenvolvimento Económico (MCOCDE), desde que não constem da lista dos paraísos fiscais elencados na Portaria n. ${ }^{\circ}$ 150/2004, de 13 de fevereiro, alterada pela Portaria n. ${ }^{\circ} 292 / 2011$, de 8 de novembro e desde que os rendimentos, pelos critérios previstos no artigo $18 .^{\circ}$ do CIRS, não sejam de considerar obtidos em território português.

Os RNH em território português que obtenham, no estrangeiro, rendimentos da categoria $\mathrm{H}$, na parte em que os mesmos, quando tenham origem em contribuições, não tenham gerado uma dedução para efeitos do.$^{\circ} 2$ do artigo $25 .^{\circ}$ do CIRS (dedução especifica do rendimento do trabalho), aplica-se o método da isenção, segundo o $\mathrm{n}^{\circ} 6$ do artigo $81 .^{\circ}$ do CIRS, bastando que se verifique qualquer das condições seguintes:

- Sejam tributados no outro Estado de origem (Estado contratante), em conformidade com CDT celebrada por Portugal com esse Estado; ou

- Pelos critérios previstos no . $^{\circ} 1$ do artigo $18 .^{\circ}$ do CIRS, não sejam de considerar obtidos em território português.

Relativamente aos rendimentos obtidos no estrangeiro em relação aos quais, por força de CDT celebrada por Portugal, seja aplicado o método da isenção com progressividade, os rendimentos estrangeiros, embora isentos, são obrigatoriamente englobados aos restantes rendimentos do sujeito passivo para efeitos de determinação da taxa aplicável no Estado da residência, segundo o $n .^{\circ} 9$ do artigo $81 .^{\circ}$ do CIRS.

Os RNH em Portugal titulares dos rendimentos isentos nos termos dos n. ${ }^{\circ} 4,5$ e 6 do artigo $81 .^{\circ}$ do CIRS (categorias A, B, E, F, G e H) podem, contudo, optar pela aplicação do método do crédito de imposto referido no $n .^{\circ} 1$ do artigo $81 .^{\circ}$ do $\mathrm{CIRS}$, sendo neste caso os rendimentos obrigatoriamente englobados para efeitos da determinação da taxa aplicável à sua tributação, com exceção dos rendimentos previstos nas alíneas c) a e) do n. ${ }^{\circ} 1$ e nos n. ${ }^{\circ} 3$ a 6 do artigo $72 .^{\circ}$ do CIRS, que não relevam, no âmbito desta opção, para determinação da taxa, segundo o.$^{\circ} 8$ do artigo $81 .^{\circ}$ do CIRS.

De notar, por último, que o artigo $72 .^{\circ}, \mathrm{n} .{ }^{\circ} 6$ CIRS não opera qualquer distinção entre os rendimentos de fonte portuguesa e os rendimentos de fonte estrangeira, considerando-se aplicável a todos os rendimentos das categorias A e B; o que significa que se os rendimentos destas duas categorias auferidos por RNH não cumprirem os requisitos da isenção do artigo $81 .^{\circ}$ do CIRS e não estiverem sujeitos à taxa especial de $20 \%$ do artigo $72 .^{\circ}$ do CIRS ficarão sujeitos às taxas gerais e progressivas do IRS do artigo $68 .^{\circ}$ do CIRS. 


\section{Comparação com outros países}

\subsection{Considerações gerais}

O "regime português não é experiência isolada ou pioneira no domínio da tributação do rendimento dos High Net Worth Individuals ou dos expatriados" (Borges \& Sousa, 2011: 713). Vários Estados adotaram formas de tributação privilegiada dirigidas a pessoas com as quais pretendem estabelecer laços não permanentes (Borges \& Sousa, 2011), que consistem na adoção de regimes fiscais próprios de atração dessas pessoas.

A atração fiscal destas pessoas é possível de duas formas distintas: através do método da isenção na eliminação da dupla tributação internacional dos rendimentos de fonte estrangeira obtidos por RNH (método da isenção integral ou método da isenção com progressividade), ou através do método do crédito de imposto ou do método da imputação (imputação integral ou imputação ordinária) dos rendimentos de trabalho dependente e independente auferidos por sujeitos passivos de IRS.

Face à diversidade de situações, analisaremos apenas alguns destes regimes que se encontram inseridos na União Europeia (UE), tais como o francês, belga, holandês, espanhol e luxemburguês, e utilizam sistemas fiscais de tributação do rendimento numa base mundial e progressivos, à semelhança do regime português.

Estes regimes podem agrupar-se em dois tipos de destinatários (Borges \& Sousa, 2011):

- Os que preveem uma tributação mitigada do rendimento de fonte estrangeira, sendo dirigidos a quem adquira uma residência permanente; $\mathrm{e}$

- Os que estabelecem tributações favoráveis do rendimento de fonte doméstica, sendo dirigidos aos expatriados e residentes temporários.

\section{2. $O$ regime francês: Régime spécial d'imposition des impatriés}

O regime fiscal francês é um sistema de cariz temporário que prevê apenas a residência temporária dos profissionais de elevado valor acrescentado (Nascimento et al., 2010). Em suma, é dirigido aos residentes temporários. Tem a designação de expatrié interne ou impatriés e dirige-se aos rendimentos de fonte francesa. O regime francês encontra-se regulado no artigo n. ${ }^{\circ} 155$-B do Code Général des Impôts (CGI).

O regime francês é aplicável aos estrangeiros destacados que exercem atividades assalariadas como trabalhadores dependentes, mas também aos trabalhadores independentes e aos que exercem cargos dirigentes nas empresas em benefício de uma entidade francesa ou estrangeira com estabelecimento estável, sucursal ou escritório de representação, que não tenham tido qualquer ligação anterior com França, isto é, um domicílio, ou tenham exercido uma atividade em França (Nascimento et al., 2010).

Os sujeitos passivos que pretendem beneficiar do regime não podem ter sido considerados residentes fiscais em França nos cinco anos anteriores ao seu destacamento ou contratação, à semelhança do que acontece com o regime português. Reunidas as condições, o regime aplica-se até ao dia 31 de dezembro do quinto ano subsequente ao da chegada a França. Este regime permite concretamente aos sujeitos passivos destacados por um empregador estrangeiro excluir do seu rendimento tributável as despesas relacionadas 
com o seu destacamento ou, em alternativa, beneficiar de uma dedução forfetária de 30\% do respetivo montante (Borges \& Sousa, 2011).

Também está previsto que se o montante do rendimento tributável for inferior à remuneração paga a um sujeito passivo numa situação semelhante, a diferença é adicionada ao rendimento tributável, assegurando-se assim que os contribuintes declarem pelo menos 0 mesmo montante de rendimento tributável (Borges \& Sousa, 2011).

Os sujeitos passivos que estão em condições de poder beneficiar do estatuto de expatrié interne ou impatriés podem optar entre beneficiar de uma isenção de 30\% da remuneração total líquida dos gastos de destacamento, com o limite de 50\%, ou uma isenção total relativamente ao complemento de remuneração auferido em virtude do destacamento (prime d'impatriation) (Nascimento et al., 2010; Borges \& Sousa, 2011). Os rendimentos brutos de fonte estrangeira podem ainda beneficiar de uma isenção parcial (até 20\%), desde que sejam realizados exclusivamente no interesse do empregador. O período de isenção é de 8 anos contados a partir da residência fiscal do sujeito passivo em França (n. ${ }^{\circ}$ I, al. 1 do art. $155 .^{\circ}$ $B$ do $(G I)$, enquanto no regime português o período de isenção é de dez anos.

A atribuição deste estatuto aos trabalhadores independentes depende de autorização da administração fiscal francesa, do exercício de determinadas atividades previstas na legislação francesa, destas representarem uma contribuição económica excecional para a França e, por sua vez, desta contribuição representar um investimento de mais de $€ 770.000$ em pequenas e médias empresas (PME) localizadas na UE ou nos Estados do Espaço Económico Europeu (EEE) (Noruega e Islândia) (Borges \& Sousa, 2011).

\section{3. $O$ regime belga: Expatriate tax regime}

O regime belga é um sistema baseado na residência temporária dos profissionais de elevado valor acrescentado, que prevê que estes sejam sujeitos à tributação universal pelos seus rendimentos mundiais.

A Bélgica criou um regime fiscal especial atrativo para os expatriados com rendimentos de fonte belga. O regime belga encontra-se regulado na Circular n. ${ }^{\circ}$ Ci.RH.624/325.294, de 8 de agosto de 1983. Este regime determina a isenção dos rendimentos de fonte estrangeira de trabalho dependente (travel exclusion), como se de não residentes se tratassem.

O regime belga é aplicável aos estrangeiros destacados que exercem atividades assalariadas como trabalhadores dependentes e desempenham cargos dirigentes de estabelecimentos estáveis de grupos internacionais, tal como as sucursais, os centros de investigação ou os escritórios de representação de grupos internacionais sediados noutros países e sem qualquer ligação ou atividade na Bélgica. O trabalhador deve ser destacado para trabalhar na Bélgica por um grupo internacional ou recrutado diretamente a partir do estrangeiro, devendo ainda demonstrar que mantém o seu centro económico no exterior, bem como fazer prova da permanência no exterior por razões profissionais.

Tal como no regime português, os estrangeiros qualificados que são enviados temporariamente para a Bélgica por empregadores estrangeiros para aí residirem, devem ser especialistas e quadros superiores estrangeiros de elevado valor acrescentado. Os profissionais qualificados - executivos, cientistas ou investigadores - devem desempenhar exclusivamente atividades que requerem conhecimento específico e/ou de responsabilidade. Também, os sujeitos passivos que pretendem beneficiar deste regime não podem ter sido considerados residentes fiscais na Bélgica nos anos anteriores ao seu destacamento ou 
contratação. Logo que estejam reunidas as condições, o regime passa a aplicar-se no prazo de seis meses a contar do primeiro dia do mês subsequente ao da chegada à Bélgica.

Uma vez admitidos como residentes temporários, os sujeitos passivos podem deduzir determinadas despesas profissionais ao rendimento tributável incorridas na Bélgica em resultado da sua permanência no país. É assim permitido excluir do rendimento tributável os subsídios ou as despesas de destacamento na Bélgica. As despesas de transporte ou alojamento não estão, por exemplo, sujeitas a qualquer limite para efeitos de apuramento do rendimento tributável. Quanto aos subsídios ou despesas de destacamento relacionadas com a atividade na Bélgica, estas estão sujeitas a um limite de $€ 11.250$ ou de $€ 29.750$ no caso específico de atividades de controlo, de coordenação ou de pesquisa científica. Estes subsídios ou despesas estão também isentas de contribuições para a segurança social quer pela entidade patronal quer pelo trabalhador, desde que sejam cumpridas as condições do regime belga. As despesas escolares encontram-se igualmente excluídas de tributação e não estão sujeitas a qualquer limite, desde que enquadradas no regime belga.

Em suma, à semelhança do que acontece com o regime português, os rendimentos de fonte estrangeira encontram-se isentos de tributação na Bélgica.

\subsection{O regime holandês: Special tax regime for expatriates - the 30\%-ruling}

O regime holandês visa, por um lado, os estrangeiros que pretendem residir um curto período de tempo no território holandês e, por outro lado, aqueles que se deslocam à Holanda para aí residirem permanentemente. Este regime destina-se aos indivíduos que anteriormente não tenham tido qualquer residência fiscal neste país, o que o distingue dos residentes permanentes e dos residentes temporários.

No caso dos residentes temporários, foi criado um regime especial de tributação que prevê que os estrangeiros (impatriados ou inward expatriates) sejam tributados como os residentes titulares de rendimentos de trabalho dependente, mas sendo-lhes atribuído uma dedução de $30 \%$ do rendimento tributável, correspondente aos custos suportados pelo empregador com a expatriação (Nascimento et al., 2010; Borges \& Sousa, 2011). O que significa que apenas $70 \%$ dos rendimentos do trabalho dependente auferidos pelos sujeitos passivos são objeto de tributação, sendo igualmente aplicável aos rendimentos do trabalho dependente auferidos fora da Holanda, de acordo com o previsto nas CDT (Borges \& Sousa, 2011).

Em termos práticos, o regime holandês criou um mecanismo de reembolso das despesas incorridas pelo trabalhador com a sua estadia ou atividade na Holanda. O empregador é responsável pelo pagamento ao trabalhador de uma "subvenção" não tributável correspondente a $30 \%$ do rendimento de trabalho tributável do trabalhador. Destina-se principalmente a executivos estrangeiros, a trabalhadores dependentes e a professores de instituições estrangeiras que temporariamente exerçam a sua atividade na Holanda. $O$ regime fiscal depende de o trabalhador ser contratado por uma entidade empregadora residente na Holanda ou por um estabelecimento estável aí localizado de uma entidade não residente.

O regime holandês vigora durante um período de oito anos e é concedido aos estrangeiros que possuam um know-how na Holanda (Borges \& Sousa, 2011), partilhando características com o regime português. O know-how é definido em função do grau de educação, experiência profissional e salário auferido, sendo necessário, após cinco anos, 
demonstrar comprovadamente à administração fiscal holandesa que o know-how continua a existir.

Este regime não confere qualquer tratamento especial ao rendimento de fonte estrangeira, em particular aos rendimentos do trabalho dependente, contrariamente ao regime português que prevê que os rendimentos de fonte estrangeira estejam isentos de tributação.

\subsection{O regime fiscal espanhol: Régimen fiscal especial aplicable a los trabajadores desplazados a territorio español}

O regime fiscal espanhol, que entrou em vigor em 1 de janeiro de 2004, com a publicação da Lei n. ${ }^{\circ}$ 62/2003, de 30 de dezembro e do Real Decreto n. ${ }^{\circ}$ 687/2005, de 10 de junho, é um regime, segundo Nascimento et al. (2010), destinado aos estrangeiros que pretendem residir um curto período de tempo em Espanha, bem como aqueles que se deslocam para aí residirem permanentemente.

O regime espanhol é particularmente favorável aos trabalhadores estrangeiros destacados para o território espanhol. Pressupõe a ausência de residência fiscal em Espanha nos anos anteriores à sua aplicação, tal como sucede com os outros regimes. Este regime permite que os trabalhadores dependentes e membros de órgãos estatutários que obtenham residência fiscal em Espanha em consequência da sua deslocação para desenvolver uma atividade em Espanha possam optar pela tributação como não residentes no ano em que se tornam residentes fiscais e nos cinco anos seguintes, nos termos do artigo 93. ${ }^{\circ}$ da Lei 35/2006, de 28 de novembro, do Impuesto sobre la Renta de las Personas Físicas, também conhecida como Ley Beckham (Nascimento et al., 2010; Borges \& Sousa, 2011).

A partir de 1 de janeiro de 2015, a Lei 26/2014, de 27 de novembro, alterou a Lei 35/2006, de 28 de novembro, do Impuesto sobre la Renta de las Personas Físicas, excluindo do regime os desportistas profissionais mas incluindo a possibilidade de aplicar o regime aos administradores de uma entidade que não tenham participação no capital social de uma sociedade ou, tendo participação, que esta seja inferior a $25 \%$.

Deixa também de ser necessário que os rendimentos de trabalho dependente se realizem efetivamente em Espanha e para uma entidade empregadora residente em Espanha, que os rendimentos de trabalho dependente não estejam isentos de tributação e que as retribuições previstas derivadas de contrato de trabalho não excedam $€ 600.000$ por ano. A partir de 1 de janeiro de 2015, o trabalhador dependente deixou assim de estar obrigado à celebração de um contrato de trabalho com uma entidade empregadora residente em Espanha, ou através de estabelecimento estável aí localizado de uma entidade não residente.

O regime espanhol prevê a cessação das isenções aplicáveis aos não-residentes de Impuesto sobre la Renta de no Residentes e que sejam considerados obtidos em Espanha a totalidade dos rendimentos de trabalho dependente, passando assim a ter em conta todos os rendimentos obtidos para efeitos de determinação da taxa a aplicar, tal como acontece com o regime português com o método da isenção com progressividade.

Os rendimentos obtidos de fonte espanhola, nomeadamente os derivados de dividendos, juros e incrementos patrimoniais, são tributados às taxas de $20 \%, 22 \%$ e $24 \%$, respetivamente. 
Os restantes rendimentos (incluindo os de trabalho dependente) são tributados à taxa de $24 \%$ até $€ 600.000$ e os que excedam $€ 600.000$, à taxa de $47 \%$, ao passo que, no regime português, são tributados à taxa de $20 \%$.

A eliminação da limitação à retribuição de $€ 600.000$ e da exigência de um contrato de trabalho confere ao regime espanhol um carácter menos exigente, mas não tão favorável como o regime português que prevê uma taxa de tributação de $20 \%$.

Contudo, os sujeitos passivos que obtenham residência fiscal em Espanha em consequência da sua deslocação antes de 1 de janeiro de 2015 poderão optar por aplicar 0 regime vigente a 31 de dezembro de 2014.

Comparativamente com o regime português, o regime espanhol aplica-se aos sujeitos passivos que sejam considerados residentes fiscais em Espanha, não o podendo ter sido durante os dez anos anteriores à sua deslocação para o território espanhol, ao passo que o regime português prevê um período de ausência de residência fiscal nos cinco anos anteriores. Por outro lado, o regime espanhol tem a duração de seis anos, contados a partir do ano da residência fiscal do sujeito passivo, e prolonga-se nos cinco anos seguintes, ao contrário do regime português que tem a duração de dez anos, contados a partir do ano da residência fiscal, durante o qual o sujeito passivo poderá beneficiar do regime. Acresce que o regime espanhol deixou de conferir qualquer tratamento especial ao rendimento de fonte estrangeira, enquanto que no regime português os rendimentos de fonte estrangeira estão isentos de tributação.

\subsection{O regime luxemburguês: Impatriate tax regime}

O regime luxemburguês é dirigido aos profissionais de elevado valor acrescentado com residência temporário no Luxemburgo.

Foi criado um regime fiscal mais favorável para os denominados impatriés com rendimentos de fonte luxemburguesa. Este regime encontra-se regulado na Circular LIR n. ${ }^{\circ}$ 95/2 de 21 de dezembro de 2010 alterada pela Circular LIR n. ${ }^{\circ}$ 95/2 de 21 de maio de 2013 e pela Circular LIR n. ${ }^{\circ}$ 95/2 de 27 de janeiro de 2014 com efeitos retroativos a 1 de janeiro de 2014.

O regime luxemburguês destina-se aos estrangeiros destacados ou contratados que exercem atividades assalariadas como trabalhadores dependentes e aos dirigentes empresariais destacados ou contratados por uma entidade luxemburguesa ou estrangeira com estabelecimento estável, sucursal ou escritório de representação no Luxemburgo e que não tenham tido uma qualquer ligação prévia - domicílio ou atividade - no Luxemburgo.

Os sujeitos passivos que pretendem beneficiar do impatriate tax regime devem estabelecer residência fiscal no Luxemburgo e não podem ter sido considerados residentes fiscais no Luxemburgo nos cinco anos anteriores ao seu destacamento ou contratação, à semelhança do que acontece no regime português, nem ter tido um domicílio fiscal a uma distância inferior a cento e cinquenta quilómetros do Luxemburgo ou ter exercido no Luxemburgo uma atividade de trabalho dependente sujeitos a retenção na fonte nos cinco anos anteriores ao seu destacamento ou contratação. Ainda de referir que os beneficiários devem exercer a sua atividade principal no Luxemburgo e auferir uma remuneração anual mínima de $€ 50.000$, não podendo os trabalhadores impatriés substituir outros trabalhadores não abrangidos por este regime.

No caso dos sujeitos passivos destacados, a Circular LIR n. ${ }^{\circ}$ 95/2 de 27 de janeiro de 2014 exige uma relação contratual entre o empregador estrangeiro e o trabalhador destacado de 
pelo menos cinco anos de antiguidade no grupo internacional, além de que deve existir um acordo contratual entre o empregador estrangeiro e a entidade luxemburguesa. $O$ trabalhador destacado goza, contudo, do direito de regresso ao país de origem no fim do período de residência.

No caso dos sujeitos passivos contratados, a Circular LIR n. ${ }^{\circ}$ 95/2 de 27 de janeiro de 2014 determina que os beneficiários devem ser especialistas qualificados (estes profissionais qualificados devem desempenhar exclusivamente atividades que requerem conhecimento específico), de elevado valor acrescentado e de difícil contratação no Luxemburgo. Uma vez reunidas estas condições, prevê-se que o regime seja aplicado até ao quinto ano subsequente ao da sua chegada ao Luxemburgo.

O regime luxemburguês permite aos sujeitos passivos destacados ou contratados por um empregador estrangeiro que sejam excluídas do seu rendimento tributável as despesas relacionadas com o destacamento ou contratação. Determina a Circular LIR n. ${ }^{\circ}$ 95/2 de 27 de janeiro de 2014 a este propósito que os sujeitos passivos que preenchem os requisitos legais poderão beneficiar de uma isenção de $30 \%$ da respetiva remuneração anual total líquida, sujeita a um limite de $€ 50.000$ ou $€ 80.000$ (solteiros ou casados), relativamente ao rendimento tributável líquido dos gastos relacionados com o destacamento, tais como as rendas, as despesas de alojamento, a licença de regresso ao país de origem e a equalização fiscal. Os sujeitos passivos poderão igualmente beneficiar de uma isenção de $8 \%$ ou $16 \%$ da respetiva remuneração mensal total líquida, sujeita a um limite de $€ 1.500$ ou $€ 3.000$ (solteiros ou casados), relativamente ao rendimento tributável líquido dos gastos relacionados com as deslocações ao país estrangeiro. Está ainda prevista isenção total relativamente às despesas de alojamento (do início ao fim do destacamento) e às propinas escolares. Esta isenção é aplicável durante um período de cinco anos contados a partir da residência fiscal do sujeito passivo no Luxemburgo, sendo este período de dez anos no regime português.

Relativamente à entidade luxemburguesa, a Circular LIR n. ${ }^{\circ}$ 95/2 de 27 de janeiro de 2014 determina que esta deve empregar pelo menos 20 trabalhadores a tempo inteiro no Luxemburgo e, caso exista há dez anos ou mais, apenas pode empregar no máximo 30\% do total de trabalhadores a tempo inteiro no Luxemburgo. Além disso, a entidade luxemburguesa é obrigada a declarar à administração fiscal luxemburguesa até 31 de janeiro de cada ano os trabalhadores impatriés que beneficiam do regime.

\section{Conclusão}

O regime fiscal do RNH é particularmente atrativo para os profissionais qualificados que exercem atividades de elevado valor acrescentado, com carácter científico, artístico ou técnico, e para os indivíduos com elevado património. Este regime é apresentado como um incentivo fiscal para os não residentes que, sendo trabalhadores dependentes, independentes, pensionistas ou membros de órgãos estatutários de pessoas coletivas, apenas pretendem estabelecer em Portugal uma residência temporária para aí auferir rendimentos, em virtude de terem sido destacados ou expatriados.

Este regime do RNH coloca Portugal à frente dos vários países. São muitos os estrangeiros que procuram Portugal para assim beneficiar deste regime de tributação. Comparativamente com o regime francês, que prevê uma isenção de $30 \%$ do rendimento tributável de fonte nacional (com limite de 50\%) e uma isenção de apenas $20 \%$ dos rendimentos de fonte estrangeira, o regime português tributa os rendimentos de fonte 
nacional em apenas $20 \%$ e isenta de tributação os de fonte estrangeira. Por outro lado, o período de isenção em França é de oito anos, enquanto no regime português o período de isenção é de dez anos.

Em relação ao regime belga, este exige uma ausência de residência fiscal, sendo no caso português a ausência de residência fiscal limitada aos cinco anos anteriores. Além disso, o belga destina-se exclusivamente a especialistas e quadros superiores, ao contrário do regime português que é mais abrangente (inclui atividades de elevado valor acrescentado ou de propriedade intelectual, industrial ou know-how). No que diz respeito ao regime de tributação, em Portugal os rendimentos de fonte nacional estão sujeitos a uma taxa de $20 \%$ e na Bélgica só estão excluídos de tributação os subsídios ou gastos com destacamento (travel exclusion). O período durante o qual o RNH poderá beneficiar do regime é de dez anos em Portugal, sendo aqui mais vantajoso o belga que não prevê qualquer limite.

Analisando em termos comparativos o regime fiscal holandês, este destina-se exclusivamente a atividades que exigem know-how, ao contrário do regime português. Por outro lado, no caso holandês, é exigido um contrato de trabalho, contrariamente ao português. Quanto ao regime de tributação, os rendimentos de fonte nacional em Portugal estão sujeitos apenas a uma taxa de $20 \%$, ao passo que na Holanda está previsto, em alguns casos, uma isenção de 30\% do rendimento tributável (subvenção não tributável) e, em outros casos, uma tributação de $70 \%$ do rendimento tributável. De destacar, por último, que o período de isenção na Holanda é de oito anos, enquanto que no regime português é de dez anos.

No caso do regime fiscal espanhol, este exige uma ausência de residência fiscal nos dez anos anteriores, sendo só de cinco anos em Portugal. Em matéria de tributação, os rendimentos de fonte nacional em Portugal estão sujeitos a uma taxa de $20 \%$ e em Espanha está previsto uma taxa de $24 \%$ para um rendimento tributável até $€ 600.000$ e uma taxa de $47 \%$ para um rendimento tributável superior a $€ 600.000$. Ainda de salientar que o período de isenção em Espanha é de um a cinco anos e em Portugal de dez anos.

Por último, o regime fiscal luxemburguês não é mais favorável na medida em que se destina exclusivamente a especialistas qualificados. Quanto ao regime de tributação, e relativamente aos rendimentos de fonte nacional, estão sujeitos em Portugal a uma taxa de $20 \%$ e no Luxemburgo prevê-se, em alguns casos, uma isenção de $30 \%$ do rendimento tributável anual (com limite de $€ 50.000$ ou $€ 80.000$ ) e, em outros casos, uma isenção de $8 \%$ ou $16 \%$ no caso de rendimento tributável mensal (com limite de $€ 1.500$ ou $€ 3.000$ ). No que toca aos rendimentos de fonte estrangeira, está previsto uma isenção em Portugal ao contrário do Luxemburgo onde não há qualquer isenção. De notar ainda que o período de isenção no Luxemburgo é de cinco anos e em Portugal de dez anos.

Em conclusão, em termos de vantagem comparativa, o regime fiscal do RNH coloca Portugal numa situação de concorrência fiscal privilegiada face aos outros países em análise neste trabalho, o que obriga a uma gestão fiscal eficiente para captar mais rendimentos e negócios estrangeiros, o que nem sempre é fácil dado a multiplicidade de regimes e de alterações legislativas nesta matéria nos vários países.

Como sugestão de investigação futura, propomos que sejam analisados, através de simulações, os vários regimes apresentados com vista a apurar mais concretamente o maior benefício fiscal em termos de poupança fiscal para o sujeito passivo. Sugerimos uma simulação em que se compare qual o imposto que um indivíduo pagaria, com o mesmo 
rendimento em cada um dos países, com vista a mostrar a vantagem em ser ou não RNH em Portugal.

\section{Referências}

Borges, R. P. \& Sousa, P. R. (2011). O novo regime fiscal dos residentes não habituais. In F. Araújo, P. Otero \& J. T. Gama (Eds.), Estudos em memória do Professor Doutor J. L. Saldanha Sanches (pp. 709-772) Volume V. Lisboa: Coimbra Editora.

Código do Imposto sobre o Rendimento das Pessoas Singulares (1988). Diário da República: n. ${ }^{\circ}$ 277/1988, 1. ${ }^{\circ}$ Suplemento, Série I de 30 de novembro, atualizado em 16 de janeiro de 2017.

Código do Imposto sobre o Rendimento das Pessoas Singulares (2017). Diário da República: n. ${ }^{\circ}$ 11/2017, 1. ${ }^{a}$ série de 16 de janeiro.

Circulaire du directeur des contributions L.I.R. $n^{\circ}$ 95/2 du 31 décembre 2010. Luxembourg.

Circulaire du directeur des contributions L.I.R. $n^{\circ} 95 / 2$ du 21 mai 2013. Luxembourg.

Circulaire du directeur des contributions L.I.R. $n^{\circ}$ 95/2 du 27 janvier 2014. Luxembourg.

Circulaire n. ${ }^{\circ} \mathrm{Ci} . \mathrm{RH} .624 / 325.294$ (1983). Service public federal finances. Belgique.

Decreto-Lei n. ${ }^{\circ} 215 / 89$ de 1 de julho. Diário da República n. ${ }^{\circ}$ 149/89 - Série I. Ministério das Finanças e da Administração Pública.

Decreto-Lei n. ${ }^{\circ} 249 / 2009$ de 23 de setembro. Diário da República n. ${ }^{\circ}$ 185/2009 - Série I. Ministério das Finanças e da Administração Pública.

Decreto-Lei n..$^{\circ}$ 2/2013 de 17 de junho. Diário da República n. ${ }^{\circ} 114 / 2013$ - Série I. Ministério das Finanças e da Administração Pública.

Decreto-Lei n. ${ }^{\circ} 162 / 2014$ de 31 de outubro. Diário da República n. ${ }^{\circ}$ 211/2014 - Série I. Ministério das Finanças e da Administração Pública.

Ferreira, R. F. \& Gonçalves, M. R (2012). A simplificação do regime dos residentes não habituais. Informação Fiscal n. ${ }^{\circ}$ 23, RFF Advogados.

Lei n. ${ }^{\circ}$ 20/2012 de 14 de maio. Diário da República n. ${ }^{\circ}$ 93/2012 - Série I. Assembleia da República.

Lei n. 64 -A/2008 de 31 de dezembro. Diário da República n. ${ }^{\circ}$ 252/2008 - 1. ${ }^{\circ}$ Suplemento, Série I. Assembleia da República.

Lei n. ${ }^{\circ} 83-C / 2013$ de 31 de dezembro. Diário da República n. ${ }^{\circ} 83-C / 2013$ - Série I. Assembleia da República.

Lei n. ${ }^{\circ} 82-E / 2014$ de 31 de dezembro. Diário da República n. ${ }^{\circ}$ 252/2014, $2^{\circ}$. Suplemento - Série $I$. Assembleia da República.

Ley 62/2003, de 30 de diciembre. Agencia Estatal. Boletín oficial del estado. España.

Ley 35/2006, de 28 de noviembre. Agencia Estatal. Boletín oficial del estado. España.

Ministère de l'Économie et des Finances (2009). Bulletin officiel des finances publiques-Impôts-Archives.

Ministère de l'Économie et des Finances (2017). Bulletin officiel des finances publiques - Impôts.

Ministère de l'Économie et des Finances (2017). Code géneral des impôts. Article 155 B.

Nascimento, R., Graça, T. M. \& Ramos, M. (2010). O novo regime fiscal do residente não habitual: 0 contribuinte volátil e o headhunting fiscal na captação de investimento. In G. Teixeira \& A. S. Carvalho (Eds.), Os 10 anos de Investigação do CIJE - Estudos Jurídico-Económicos (pp. 857-880). Coimbra: Almedina.

Portaria n. ${ }^{150 / 2004}$ de 13 de fevereiro. Diário da República n. ${ }^{\circ}$ 37/2004 - Série I-B. Ministério das Finanças e da Administração Pública.

Portaria n. ${ }^{\circ} 12 / 2010$ de 7 de janeiro. Diário da República n. ${ }^{\circ}$ 4/2010 - Série I. Ministério das Finanças e da Administração Pública.

Portaria n. ${ }^{\circ}$ 292/2011 de 8 de novembro. Diário da República n. ${ }^{\circ}$ 214/2011 - Série I. Ministério das Finanças e da Administração Pública.

Real Decreto 687/2005, de 10 de junio. Agencia Estatal. Boletín oficial del estado. España.

JOSÉ DE CAMPOS AMORIM é doutorado em Direito Público pela Faculdade de Direito da Universidade de Evry em Paris, exerce atualmente as funções de Professor Coordenador da área do Direito Fiscal no Instituto Superior de Contabilidade e Administração do Porto (ISCAP). Tem uma experiência como docente em várias instituições de ensino superior. Publicou vários trabalhos no domínio do Direito Fiscal. É membro do Conselho Científico do ISCAP, do Conselho Editorial da Revista de Ciências Empresariais e Jurídicas e do Centro de Estudos Organizacionais e Sociais do Politécnico do Porto 
(CEOS.PP). Colabora igualmente no projeto editorial Lexit (códigos fiscais anotados e comentados). Morada institucional: ISCAP, Rua Jaime Lopes Amorim, s/n. 4465-004 S. Mamede de Infesta, Portugal.

Submetido em 15 janeiro 2017

Aceite em 31 julho 2017 